\title{
Biosorpsi Ion Logam Zink (II) Dalam Larutan Menggunakan Daun Kari (Murraya koenigii)
}

\author{
Bhayu Gita Bhernama \\ Prodi Kimia Fakultas Sains dan teknologi Uin Ar-Raniry Banda Aceh \\ Jl. Syeikh Abdul Rauf Kopelma Darussalam Banda Aceh \\ Email : deta.chavez1678@gmail.com
}

\begin{abstract}
Absorption heavy metal of Zn (II) ion using curry leaf (murraya koenigii) has been done. This research is aimed to determine the concentration of Zn (II) metal ion can be absorbed by curry leaf (murraya koenigii). The ability of curry leaves to absorb the Zn (II) metal ions has been evaluated by the variation of $\mathrm{pH}$ solution, concentration, particle size of biomaterial weight. The absorbed metal ion content was measured using an atomic absorption spectrophotometer (ASS). The results showed the optimum condition of heavy metal Zn (II) ion absorption using curry leaves (murraya koenigii) with $\mathrm{pH} 5$ absorption capacity of $0.611 \mathrm{mg} / \mathrm{g}$, particle size $150 \mu \mathrm{m}$ absorption capacity $0.689 \mathrm{mg} / \mathrm{g}$, concentration $50 \mathrm{ppm}$ with absorption capacity $0.443 \mathrm{mg} / \mathrm{g}$ and material weight $0,5 \mathrm{~g}$ absorption capacity $1.505 \mathrm{mg} / \mathrm{g}$. Based on the Langmuir isotherm equation obtained the maximum absorption capacity of Qmax -0.127. FTIR analysis results show the presence of hydroxyl groups which can bind Zn (II) metal ions
\end{abstract}

Keywords : heavy motal ion Zn (II), adsorption, curry leaf (murraya koenigii)

\section{PENDAHUluan}

Pencemaran lingkungan disebabkan oleh aktifitas manusia diberbagai bidang, baik dibidang industri, pertambangan, teknologi, transportasi yang berdampak pada kehidupan manusia. Dampak pencemaran lingkungan yang ditimbulkan antara lain pencemaran air. Pencemaran air disebabkan oleh limbah logam berat. Limbah logam berat menyebabkan pencemaran serius terhadap lingkungan apabila kandungan logam berat melebihi ambang batas dan mempunyai sifat racun yang berbahaya apabila terakumulasi serius didalam tubuh manusia (Nurhasni, 2012)

Logam berat mempunyai berat jenis besar dari $5 \mathrm{~g} / \mathrm{cm}^{3}$ dan nomor atom antara 22 sampai 92, terletak pada perioda tiga sampai tujuh. Unsur-unsur yang termasuk logam berat adalah besi, timah, kadmium, tembaga, seng, mangan, dan lain. (Sumiarjo, 2008)

Berbagai metoda pemisahan logam berat telah digunakan seperti metoda pertukaran ion, pengendapan kimia, membran, penyerapan dan ekstraksi pelarut. Selain daripada itu, pemisahan logam berat dari limbah cair dapat memanfaatkan material biologi sebagai bahan penyerap (biosorben),seperti alga (Buhani, 2006), padi dan genjer (Nurhasni, 2012), ampas tebu (Refilda, 2001), chitin dan chitosan (Prakash, et, al 2011), kembang sepatu (Vankar et, al, 2011), sukun (Linda, et,al 2012), dan kulit manggis (Zein R, et, al, 2010). 
Daun kari (Murraya Koenigii) merupakan tanaman yang terdapat didaerah Aceh, biasanya dimanfaatkan sebagai bumbu penyedap pada masakan dikarenakan daunkari (murraya koenigii) memberikan rasa dan bau yang nikmat pada makanan. Daun kari (Murraya Koenigii) merupakan famili Rutaceae, sering digunakan pada masakan india. Daun kari (Murraya Koenigii) mempunyai daun menyerupai sirip dengan 11-21 bagian pada setiap ranting, bunga putih dan harum, buah dapat dimakan akan tetapi biji bersifat racun (Rastina, dkk, 2015)

Pada penelitian ini dilakukan penyerapan logam $\mathrm{Zn}$ (II) menggunakan daun kari (Murraya koenigii) sebagai material penyerap (biosorben). Optimasi penyerapan logam $\mathrm{Zn}$ (II) dengan daun kari (Murraya koenigii) diuji dengan variasi $\mathrm{pH}$, kosentrasi, ukuran partikel dan berat biomaterial.

\section{METODE PENELITIAN}

\section{Alat}

Spektofotometer serapan atom (Raylight WFX-320, BRAIC, China), FTIR (FTIR-460 Plus, Jasco, Japan), neraca digital (KERN 220-4M, Germany), pH Universal (Merck), blender, kertas saring, dan peralatan gelas lainnya.

\section{Bahan}

Daun Kari (diambil di beberapa daerah banda aceh), zat kimia yang digunakan semuanya keluaran merck (Darmstad, Jerman ). $\mathrm{ZnCl}_{2}, \mathrm{HNO}_{3} 65 \%, \mathrm{NaOH}$, etanol destilasi dan air destilasi.

\section{Prosedur Penelitian}

\section{Pembuatan Larutan Reagen}

\section{Asam Nitrat $0,1 \mathrm{~N}$}

$\mathrm{HNO}_{3} 65 \%$ dimasukkan $6,78 \mathrm{~mL}$ ke dalam labu ukur $1000 \mathrm{~mL}$ dan diencerkan dengan akuades sampai tanda batas.

\section{$\mathrm{NaOH} 0,1 \mathrm{~N}$}

$\mathrm{NaOH}$ dimasukkan 0.4 gram kedalam gelas piala $100 \mathrm{~mL}$ kemudian diencerkan dengan akuades sampai tanda batas.

Larutan Standar Zn(II) $1000 \mathrm{mg} / \mathrm{L}$

Larutan standar $\mathrm{Zn}$ (II) dibuat dengan menimbang $\mathrm{ZnCl}_{2}$ sebanyak 0,2096 $\mathrm{g}$ dan dilarutkan dalam labu $100 \mathrm{ml}$ dengan akuades sampai tanda batas. 


\section{Perlakuan Awal Biomaterial Daun Kari (Murraya Koenigii)}

Daun Kari (Murraya Koenigii) yang diambil di beberapa daerah banda aceh, dibersihkan, kemudian dicuci dengan air bersih dan dijemur di udara terbuka. Setelah kering kemudian dihaluskan dengan cara diblender dan diayak dengan ayakan berdasarkan ukuran partikel yang akan dipakai $(150 \mu \mathrm{m}, 180 \mu \mathrm{m}, 250 \mu \mathrm{m}, 425 \mu \mathrm{m})$. Daun Kari (Murraya Koenigii) dengan ukuran tersebut direndam dalam larutan $\mathrm{HNO}_{3}$ 0,1 M selama 2 jam sambil sesekali diaduk. Hasil rendaman disaring kemudian dicuci dengan air destilasi sampai netral kemudian dikeringkan kembali.

\section{Pengukuran FT/IR}

Sebelum penyerapan.

Biomaterial dipanaskan selama 30 menit dengan temperature $50^{\circ} \mathrm{C}$. Setelah itu sampel didinginkan dan disimpan dalam desikator, kemudian sampel diukur dengan FTIR.

Setelah penyerapan

Biosorben kering yang telah digunakan untuk menyerap ion logam disimpan didalam desikator kemudian diukur dengan FTIR.

\section{Penentuan Kondisi Optimum Daun Kari (Murraya Koenigii)}

Untuk mengetahui kemampuan penyerapan ion logam $\mathrm{Zn}$ (II) oleh Daun Kari maka dilakukan penentuan kondisi optimum berupa $\mathrm{pH}$ ion logam, ukuran partikel daun kari, konsentrasi ion logam, dan berat daun kari.

Pengaruh $\mathrm{pH}$ ion logam

Absorben dengan ukuran partikel $150 \mu \mathrm{m}$ sebanyak $1 \mathrm{~g}$ dimasukkan kedalam kolom dan dielusi dengan $20 \mathrm{~mL}$ larutan ion logam konsentrasi $50 \mathrm{mg} / \mathrm{L}$ dengan $\mathrm{pH}$ larutan ion logam yang divariasikan 1, 3, 5, 7 dan 9 dengan kecepatan alir larutan ion logam yaitu $2 \mathrm{~mL} / \mathrm{menit}$. Filtrat yang dihasilkan dianalisa dengan spektrofotometer serapan atom. Dari perlakuan ini diperoleh pH ion logam optimum.

Pengaruh ukuran partikel

Absorben ditimbang $1 \mathrm{~g}$ dengan ukuran partikel $150 \mu \mathrm{m}$, kemudian dimasukan kedalam kolom, dan dielusi dengan $20 \mathrm{~mL}$ larutan ion logam konsentrasi $50 \mathrm{mg} / \mathrm{L}$ dengan kecepatan alir 2 $\mathrm{mL} /$ menit pada $\mathrm{pH}$ optimum. Filtrat yang dihasilkan dianalisa dengan spektrofotometer serapan atom. Hal ini juga dilakukan pada ukuran partikel 180, 250, dan $425 \mu \mathrm{m}$ sehingga diperoleh ukuran partikel absorben optimum.

Pengaruh konsentrasi larutan terhadap penyerapan ion logam

Absorben ditimbang $1 \mathrm{~g}$ dengan ukuran partikel optimum, kemudian dimasukan kedalam kolom, dan dielusi dengan $20 \mathrm{~mL}$ larutan ion logam konsentrasi yang divariasikan 5, 10, 15, 20, 25, 30, 35, 40, 45 dan $50 \mathrm{mg} / \mathrm{L}$ dengan $\mathrm{pH}$ optimum pada kecepatan alir $2 \mathrm{~mL} / \mathrm{menit}$. Filtrat yang 
dihasilkan dianalisa dengan spektrofotometer serapan atom. Dari perlakuan in diperoleh konsentrasi ion logam optimum

Pengaruh berat biomaterial terhadap penyerapan ion logam

Absorben ditimbang yang beratnya divariasikan 0,$5 ; 1 ; 1,5 ; 2$ dan 2,5 g dengan ukuran partikel optimum, kemudian dimasukan kedalam kolom, dan dielusi dengan $20 \mathrm{~mL}$ larutan ion logam konsentrasi dan $\mathrm{pH}$ optimum dengan kecepatan alir optimum. Filtrat yang dihasilkan dianalisa dengan spektrofotometer serapan atom. dari perlakuan ini diperoleh berat absorben optimum.

\section{HASIL DAN PEMBAHASAN}

\section{Analisis FTIR}

Spektrofotometer inframerah digunakan untuk mengidentifikasi gugus fungsi dari sebuah biomaterial. Gugus fungsi sangat berperan dalam proses penyerapan ion logam yang tergantung kepada banyak dan jenis gugus fungsi, proses interaksi, struktur kimia dan afinitas biosorben dengan ion logam.Spektrum FTIR dari penyerapan daun kari sebelum dan sesudah adsorbsi dapat dilihat pada gambar 1 dan 2 .

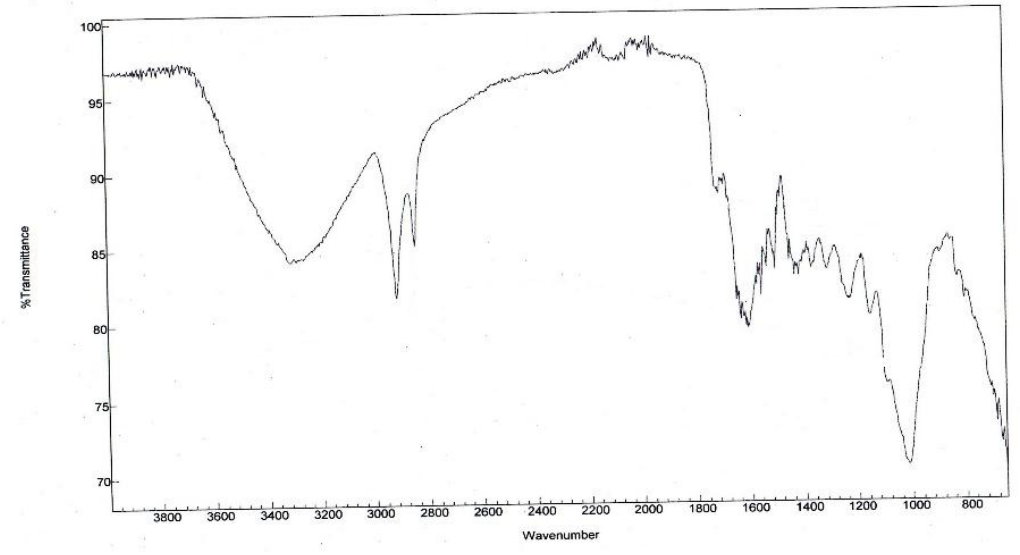

Gambar 1. Spektrum FTIR daun kari (murraya koenigii) sebelum penyerapan ion logam Zn (II) 


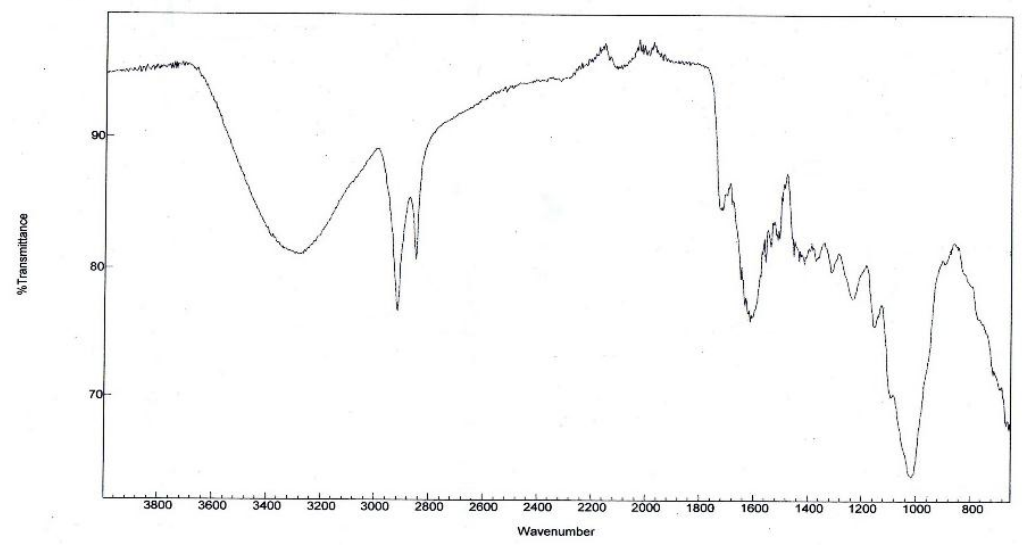

Gambar 2. Spektrum FTIR daun kari (murraya koenigii) setelah penyerapan ion logam Zn (II)

Beberapa pergeseran frekuensi sebelum dan sesudah penyerapan ion logam terlihat pada tabel 1 dan 2.

Tabel 1. Gugus Serapan daun kari sebelum proses biosorpsi ion logam

\begin{tabular}{ll}
\hline$\lambda$ & Gugus fungsi \\
\hline 397,283 & Uluran dari gugus $-\mathrm{OH}$ \\
$2918,903-2850,807$ & Regangan C-H \\
$1725,162-1610,002$ & Ulur C = O \\
1239,532 & Amina \\
1517,171 & Nitro \\
$1157,921-1019,962$ & C-O kuat \\
\hline
\end{tabular}

Tabel 2. Gugus Serapan daun kari setelah proses biosorpsi ion logam

\begin{tabular}{ll}
\multicolumn{2}{c}{ Tabel 2. Gugus Serapan daun kari setelah proses biosorpsi ion logam } \\
\hline$\lambda$ & Gugus fungsi \\
\hline 384,329 & Uluran dari gugus $-\mathrm{OH}$ \\
$2918,761-2850,800$ & Regangan C-H \\
$1725,028-1608,991$ & Ulur C = O \\
1315,737 & Amina \\
1516,637 & Nitro \\
$1157,536-1016,815$ & C-O kuat \\
\end{tabular}

Pengaruh pH terhadap kapasitas penyerapan ion logam Zn (II) 
$\mathrm{pH}$ merupakan parameter penting dalam proses biosorbsi karena $\mathrm{pH}$ mempengaruhi kelarutan ion logam dalam larutan. Kemampuan ion logam lain untuk mengikat pada permukaan biomaterial mempengaruhi muatan pada permukaan selama reaksi berlangsung.

Pada $\mathrm{pH}$ rendah penyerapan ion logam dihalangi oleh ion hidronium $\left(\mathrm{H}^{+}\right)$yang mengelilingi permukaan biosorben sehingga terjadi persaingan antara ion logam dan ion hidronium $\left(\mathrm{H}^{+}\right)$ mengakibatkan menurunnya kapasitas penyerapan.

Pengaruh variabel $\mathrm{pH}$ terhadap kosentrasi penyerapan ion logam $\mathrm{Zn}$ (II) menggunakan daun kari (Murraya koenigii) dapat dilihat pada gambar 1. Dari gambar 3 terlihat bahwa kondisi optimum penyerapan pada pH 5 dengan kapasitas penyerapan 0,611 mg/g (0,611 mg ion logam / g adsorben), dimana kosentrasi awal ion logam Zn (II) 50 ppm.

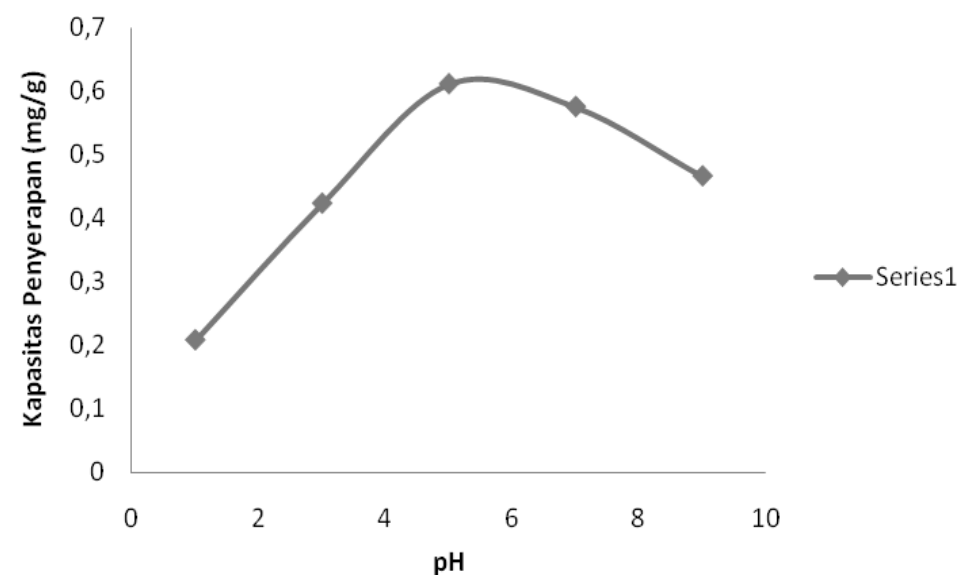

Gambar 3.Pengaruh pH terhadap kapasitas ion logam $\mathrm{Zn}(\mathrm{II})$ terhadap penyerapan daun kari (ukuran partikel absorben $\leq 150 \mu \mathrm{m}$, laju alir larutan ion logam $2 \mathrm{ml} / \mathrm{menit}$, berat absorben $1 \mathrm{~g}$, dan konsentrasi larutan ion logam 50mg/L)

\section{Pengaruh ukuran partikel terhadap kapasitas penyerapan ion logam Zn (II)}

Penyerapan ion logam Zn (II) pada daun kari dilakukan pada ukuran partikel biosorben 150, 180, 250, dan 425 mm. Dari hasil penelitian didapatkan penyerapan ion logam Zn (II) dengan biosorben daun kari terjadi pada kondisi optimum ukuran partikel $150 \mu \mathrm{m}$ dengan kapasitas penyerapan $0,689 \mathrm{mg} / \mathrm{g}$. Pengaruh ukuran partikel terhadap kapasitas ion logam $\mathrm{Zn}(\mathrm{II})$ terhadap penyerapan daun kari dapat dilihat pada gambar 4. 


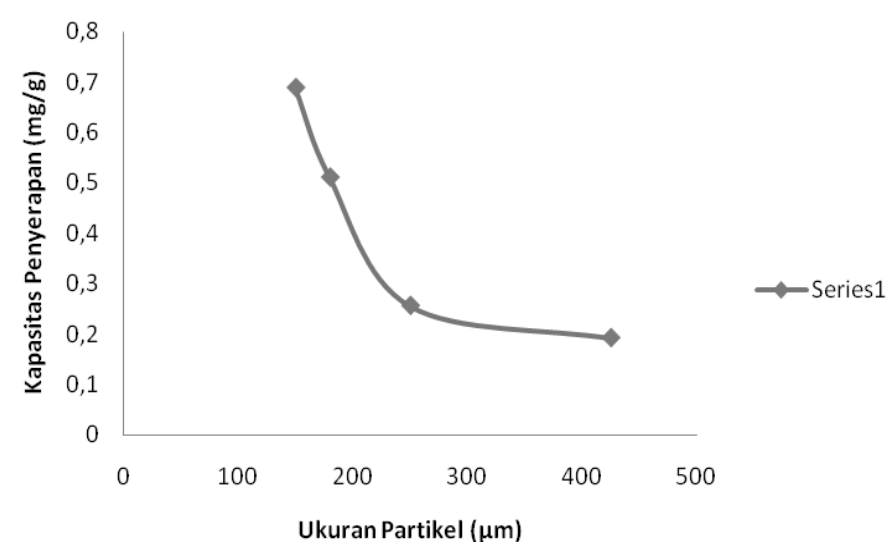

Gambar 4. Pengaruh ukuran partikel daun kari $(\mu \mathrm{m})$ terhadap penyerapan ion $\mathrm{Zn}$ (II) $(\mathrm{pH}$ larutan ion logam optimum, laju alir larutan ion logam $2 \mathrm{ml} / \mathrm{menit}$, berat absorben $1 \mathrm{~g}$, dan konsentrasi larutan ion logam 50mg/L)

Israel dan Eduok (2012) pada penelitiannya mengamati penyerapan optimum logam Zn(II) terjadi pada ukuran partikel $180 \mu \mathrm{m}$. Hal ini dikarenakan peristiwa adsorpsi terjadi pada permukaan biomaterial sehingga tingkat penyerapan bergantung pada luas permukaan. Semakin kecil ukuran partikel suatu biomaterial semakin besar penyerapan yang terjadi.

\section{Pengaruh konsentrasi ion logam terhadap kapasitas penyerapan ion logam Zn (II)}

Konsentrasi ion logam berhubungan dengan banyaknya ion logam yang dapat berinteraksi dengan sisi aktif material penyerap. Sehingga semakin banyak ion logam dalam larutan maka semakin banyak kemungkinan terjadinya interaksi dengan sisi aktif absorben sehingga kapasitas penyerapannya meningkat. Tetapi pada saat tertentu jumlah sisi aktif sama dengan jumlah ion logam, pada saat tersebut penyerapan yang terjadi akan konstan sehingga kapasitas penyerapan akan menurun dengan meningkatnya konsentrasi (Ramadhan dan Handajani, 2007).

Pengaruh konsentrasi ion logam terhadap kapasitas penyerapan daun kari dapat dilihat pada Gambar 5. 


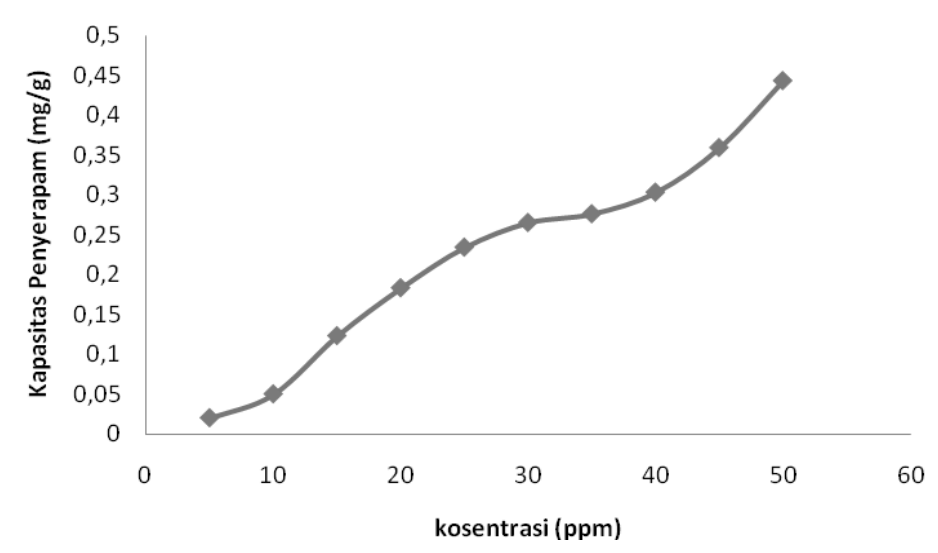

Gambar 5. Pengaruh konsentrasi larutan ion logam Zn (II) terhadap kapasitas penyerapan daun kari (Murraya koenigii) ( $\mathrm{pH}$ larutan ion logam optimum, ukuran partikel absorben optimum $(\mu \mathrm{m})$, laju alir larutan ion logam $2 \mathrm{ml} /$ menit, dan berat absorben $1 \mathrm{~g}$ )

Penyerapan ion logam Zn (II) yang divariasikan pada kosentasi 5, 10, 15, 20, 25, 30, 35, 40, 45 dan $50 \mathrm{ppm}$, diperoleh kosentrasi optimum penyerapan ion logam pada konsentrasi $50 \mathrm{ppm}$ dengan kapasitas penyerapan $0,443 \mathrm{mg} / \mathrm{g}$. Konsentrasi suatu ion logam dapat dihitung dan dijelaskan berdasarkan kapasitas penyerapan dengan menggunakan adsorbsi isotherm.

\section{Kapasitas Serapan Maksimum}

Kapasitas serapan maksimum diperoleh dari persamaan Isoterm Langmuir sehingga didapat grafik antara 1/C versus 1/Q seperti Gambar 4

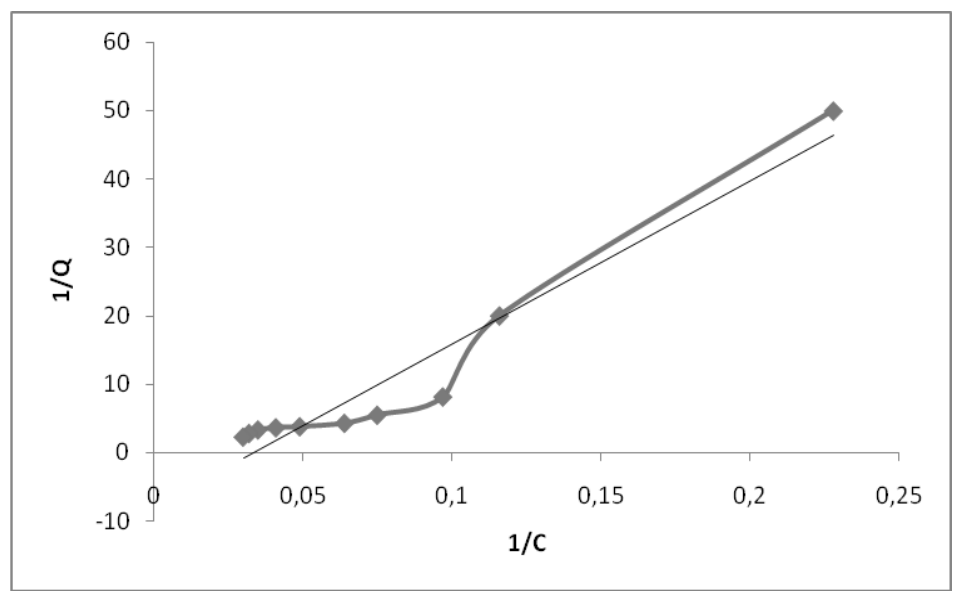

Gambar 6. Linearitas Langmuir untuk penyerapan ion logam), Zn oleh Daun Kari (Murraya koenigii) 
Dari gambar 6 diatas diperoleh persamaan isothermal Langmuir dan selanjutnya digunakan untuk menentukan kapasitas penyerapan maksimum (Qm).

Penyerapan Isoterm menggambarkan hubungan antara zat teradsorpsi dalam jumlah berat adsorben (daun kari) tertentu dalam satuan keseimbangan. Proses adsorpsi yang terjadi antara ion logam Zn (II) dan adsorben (daun kari).

Penentuan kapasitas adsorpsi sebagai kajian termodinamika digunakan persamaan Langmuir. Isoterm adsorpsi Langmuir dapat dinyatakan dengan persamaan :

$$
1 / \mathrm{Q}=1 / \mathrm{Qm}+1 / \mathrm{bQmC}
$$

Di mana $\mathrm{C}$ adalah konsentrasi ion logam $(\mathrm{mg} / \mathrm{L}), \mathrm{Q}$ adalah jumlah zat teradsorpsi per gram adsorben $(\mathrm{mg} / \mathrm{g})$, dan $\mathrm{Qm}$ adalah kapasitas penyerapan maksimum $(\mathrm{mg} / \mathrm{g})$. Hubungan antara kapasitas penyerepan dan konsentrasi ion logam dapat dilperoleh dengan memplotkan data yang diperoleh dari hasil penelitian ke grafik 1/C dengan 1/Q menghasilkan garis lurus dengan slop 1/bQm dan intersep 1/Qm. Dari perhitungan didapat kapasitas penyerapan maksimum untuk ion logam $\mathrm{Zn}$ (II) -0,127 dengan koefisien korelasi ( $\left.\mathrm{R}^{2}\right)$ 0,957.

\section{Pengaruh berat biomaterial terhadap kapasitas penyerapan ion logam Zn (II)}

Variasi berat daun kari (Murraya koenigii) yang yang digunakan untuk penyerapan ion logam $\mathrm{Zn}$ (II) adalah 0,5 g, 1 g, 1,5 g, 2 g, dan 2,5 g. Hasil pengukuran variasi berat biosorben terhadap penyerapan ion logam ditunjukan pada Gambar 7.

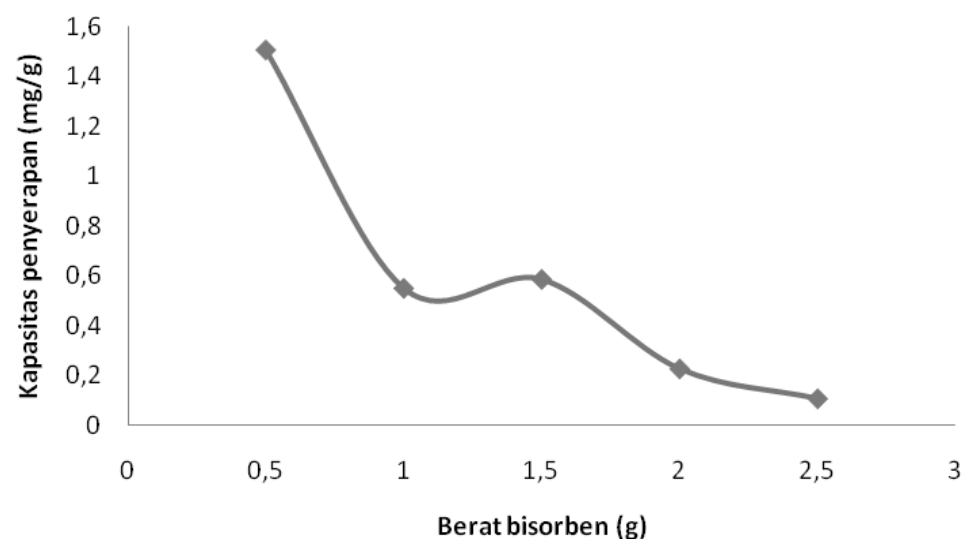

Gambar 7. Pengaruh berat biosorben terhadap kapasitas penyerapan ion logam $\mathrm{Zn}$ (II) (pH larutan ion logam optimum, ukuran partikel absorben optimum $(\mu \mathrm{m})$, laju alir larutan ion logam optimum (ml/menit), dan konsentrasi larutan ion logam optimum (mg/L))

Semakin besarnya massa biosorben yang digunakan maka semakin banyak sisi aktif yang memungkinkan banyaknya terjadi interaksi dengan ion logam. Akan tetapi penyerapan ion 
logam $\mathrm{Zn}$ (II) menggunakan daun kari didapatkan kondisi optimum berat biosorben 0,5 g dengan kapasitas penyerapan 1,505 mg/g. Menurut Pitriani pipit, 2010 penurunan penyerapan disebabkan karena larutan menjadi kental sehingga proses penyerapan tidak sempurna.

\section{PENUTUP}

Dari hasil penelitian dapat disimpulkan bahwa penyerapan maksimum ion logam Zn (II) menggunakan daun kari (Murraya koenigii) terjadi pada pH 5 kosentrasi 50 ppm ukuran partikel $150 \mu \mathrm{m}$ dan berat biomaterial 0,5 g. Kapasitas serapan maksimum daun kari berdasarkan isoterm langmuir Qmax -0,127. Dari spektrum FTIR dapat dilihat gugus yang menyebabkan penyerapan pada daun kari (Murraya koenigii) adalah gugus fungsi O-H pada frekuensi 397,283, C = O pada frekuensi 1725, 162 dan gugus $\mathrm{N}$ amina dan nitro pada frekuensi 1239, 532 dan 1517,171.

\section{DAFTAR PUSTAKA}

Babarinde. N.A.A,. Babalola. J. O., Adegoke. J., George. E O.,Henrietta O. Okeke and Ayoola T. Obagbemi. 2012. Kinetic, Equilibrium, and Thermodynamic Studies of the Biosorption of $\mathrm{Cd}(\mathrm{II}), \mathrm{Pb}(\mathrm{II})$, and $\mathrm{Zn}(\mathrm{II})$ from Aqueous Solutions using Coconut (Cocos nucifera) Leaf. The Pacific Journal of Science and Technoßogy. 13 (1).

Buhani, Suharso and Zipora sembiring, 2006. Biosorpsi of metal ions $\mathrm{Pb}(\mathrm{II}), \mathrm{Cu}$ (II) and $\mathrm{Cd}(\mathrm{II})$ )n Sargassum Duplicatum Immobilized Silica Gel Matrix. Ind J. Chem., 2006, 6(3): 245-250

Israel, U and Eduok, U. M. 2012. Biosorption of zinc from aqueous solution using coconut (Cocos nucifera L) coir dust. Scholars Research Library. 4 (2): 809-819.

Linda B., L. Lim, N. Priyantha, D. T. B. Tennakoon, M. K. Dahri. 2012. Biosorption of cadmium(II) and copper(II) ions from aqueous solution by core of Artocarpus odoratissimus. Environ Sci Pollut Res. 19: 3250-3256

Nurhasni Hendrawati, Mubzah Saniyah., 2012, Penyerapan ion logam Cd dan Cr dalam limbah menggunakan sekam padi, 310-318

Pitriani, Pipit. 2010. Sintesis dan Aplikasi Kitosan dari Cangkang Rajungan (Potunus Pelagius) sebagai Penyerap Ion Besi (Fe) dan Mangan (Mn) Untuk Pemurnian Natrium Silika). Skripsi. Program Studi Kimia Fakultas Sains dan Teknologi. Universitas Islam Negeri Syarif Hidayatullah. Jakarta

Prakash N., P. N. Sudha., N. G. Renganathan. 2012. Copper and cadmium removal from synthetic industrial wastewater using chitosan and nylon 6. Environ Sci Pollut Res. 19: 2930-2941.

Rastina, Minawarti Sudarwono, Letje Wientarsih., 2015. Aktifitas Antibakter Ekstrak Etanol Daun Kari (Murraya Koenigii) terhadap Staphylococus Aureus., E. Coli dan Pseudomonas sp., Jurnal Kedokteran Hewan., 9 (2): 185 - 188 
Ramadhan, B dan Hanjani, M. 2007. Biosorpsi logam berat Cr (VI) dengan menggunakan biomass Saccharomyces cerevisiae. ITB. Bandung

Sumiarjo., Y. Wasito., 2008. Preparasi dan penentuan logam berat $\mathrm{Cu}, \mathrm{Cr}$ dan Mn dalam cuplikan limbah percetakan dengan metoda SSA., Posiding seminar penelitian dan pengelolaan perangkat nuklir., : 245-248

Vankar P. S., R. Sarswat, R. Sahu. 2012. Biosorption of Zinc Ions from Aqueous Solutions onto Natural Dye Waste of Hibiscus rosa sinensis: Thermodynamic and Kinetic Studies. Environmental Progress \& Sustainable Energy. 31(1)

Zein, R., R. Suhaili, F. Earnestly, Indrawati, E. Munaf. 2010. Removal of Pb(II), Cd(II), and $\mathrm{Co}$ (II) from aqueos solution using Garcinia mangostana L fruit shell. Journal of Hazardous Materials. 18 : 52-56 